\title{
INCORPORATING PARTICIPATORY PLANNING AND QUALITY FUNCTION DEPLOYMENT IN URBAN PLANNING
}

\author{
Noora Buchiri ${ }^{1}$, Bader Al Mannai ${ }^{2}$, Saad M. A. Suliman ${ }^{3}$ \\ ${ }^{1}$ Urban Planning Directorate, Ministry of Municipalities Affairs and Urban Planning, \\ Manama, Bahrain \\ ${ }^{2}$ Department of Mechanical Engineering, University of Bahrain, Isa Town, Bahrain \\ ${ }^{3}$ Department of Mechanical Engineering, University of Bahrain, Isa Town, Bahrain
}

\begin{abstract}
Urban Planning is a technical process concerned with the control of the use of land and design of urban environment to guide and ensure the orderly development of settlements and communities. Outcomes from the urban planning process are detailed plans. In Bahrain the detailed plans are developed through a lengthy two-stage process, namely, design and implementation. During this lengthy process the documented design variations were found to be the main cause for implementation delay. In addition, it was discovered that land owners exclusion from the urban planning process caused major disagreements, between the urban planning authorities and the land owners. Accordingly, this paper presents an investigation into the applied urban planning process in Bahrain, and proposes a solution that incorporates Quality Function Deployment (QFD) technique. The study is based on face-to-face interviews, questionnaire, Delphi method, and a case study (North Tubli). The results of this study concluded that using participatory planning and QFD within the urban planning process enables evaluation of the different alternative plans, based on scientific and systematic procedures. In addition, it ensures that land owners and community members requirements are satisfied.
\end{abstract}

\section{KEYWORDS}

Urban planning, Participatory planning, Quality Function Deployment.

\section{INTRODUCTION}

Planning is setting out a clear strategy to meet specific societal objectives, and it is a field that can be applied to all human activities [1]. The focus of this paper is on a special type of planning termed urban planning. According, to Hall and Tewdwr[2], urban planning, is defined as planning a geographical component that will provide spatial structure of activities. While Bracken [1], considers urban planning as a process of a series of actions taken in sequence to achieve a specific result. That means urban planning can be divided into activities carried out in sequence to achieve societal goals. Two stages, namely, design and implementation should complement each other for urban plans to be successful.

Urban planning is developed to serve the general public interest since the 1960's, however, in Bahrain the concerned public (land owner's and community members) are excluded from the design stage. This exclusion has resulted in delaying major implementation plans. Eight out of twenty approved plans are not implemented yet [3]. This implies that the current urban planning process followed in Bahrain needs revision. Therefore, this study analyzes the current urban planning process followed in Bahrain, to identify the main reasons for delays and failures in

DOI:10.5121/civej.2017.4101 
implementing the detailed urban plans. In addition, this study presents a modified urban planning process that incorporates participatory planning through Quality Function Deployment (QFD) technique.

\section{LITERATURE REVIEW}

Town and country planning or urban planning is formed into its recent shape since the 1960's. Most of the current planning theories still being implemented are developed by planners and theorists who first identified urban planning as a scientific process [4,5,6]. Keeble and McLoughlin[4,5], were the first authors who introduced these theories. The first theory is based on a system view of planning and describes the stages of urban planning in technical and mathematical term. The concept of "Survey - Analysis - Plan" has been developed and implemented, but there still exists a problem of not fully comprehending the way cities functioned. This concept focuses on the design part of planning ignoring the problems that may occur during the implementation stage; this is the main reason for this theory to be abandoned [5]. Whereas, the second theory is a rational view of the planning process, it is based on the Decision Theory that is a general scientific theory consisting of five stages. This theory disregards the fact that urban planning process does not stop after implementing the most feasible alternative and monitoring its results [4].

The two theories focus on selecting the right alternative and taking the correct decision (plan) to be implemented, nonetheless, it disregards the needs of land owners and community members who live in the targeted areas. This led to residents resistance of accepting the new cities plans proposed during the 1960's. The main issues raised after proposing the design of the new roads networks in their cities and lands, were the transition of their neighbourhoods into hazardous, sound and air polluted cities [7]. Taylor [7] suggested that the urban planners should be more involved in the political process and act as advocate on behalf of the public during the planning process. This lead to the idea of public participation or what is called participatory planning, which is considered the core of this study. The idea of "Public Participation" within the process of "Urban Planning" was first introduced in the British laws following "The Town and Country Planning Act 1947 [7]. It requires the planning authorities to publicize applications to get planning permissions from the concerned parties, who are mainly the neighboring public living within the same neighbourhood. The implementation plans are required to be publicized to the general public to get their opinions and objections before the implementation takes place.

Urban Planning is a process with a series of actions followed to get unique results. It consists of two main stages, design stage and implementation stage [8]. Balta et al. [8] defines the design stage as the creation of a medium (design plan) for operating the decision making mechanisms. Whereas, the urban planning process in Turkey, has been developed through three periods [9]. The first period, from 1923 to 1950, urban planners were just designers focusing on following the design dimensions. Followed by the second period, from 1950 to 1980, when the application of the development law was enforced. The last period, after 1980, three major issues in urban planning were highlighted: incorporating urban design; sustainability; and finally public participation in planning.

In Bahrain, the urban planning process follows the same two main stages, namely, design and implementation [3]. Although this solves many planning problems, it un-intentionally creates new problems. A major problem that occurs, involves land owners' rejections that eventually increases the time span of the implementation stage. Consequently, the proposed solution involves the application of "Participatory Planning" through the participation of the land owners in the urban planning process throughout the design and implementation stages. 
Quality Function Deployment (QFD) is a technique that helps companies to determine their customers' requirements, and translates them into attributes incorporated within the products and services through the design and production, to ensure customers satisfaction [10]. The QFD technique is commonly used to enhance product and service design. In addition, this technique was applied in non-product applications, such as curriculum development, manufacturing automation technologies selection, and architectural layout design [10, 11, 12, 13, 14].

Therefore, applying the QFD technique within the urban planning process will ensure incorporating the customers' (land owners) needs and requirements. In addition, it will enable alternative plans evaluation and selection, based on scientific and systematic methodology.

\section{RESEARCH METHODOLOGY}

A thorough investigation of the research problem is conducted to identify the gap in the currently applied urban planning process in Bahrain. Questionnaires, face-to-face interviews, and meetings were conducted after deciding on the sample size. Four techniques were used for collecting data:

- General Directorate of Urban Planning [3] documents and archival records such as: urban planning laws; ISO approved procedures; implemented detailed plans' latest progress reports; and Bahrain national planning development strategies.

- Face-to-face interviews conducted with professional urban planners.

- Face-to-face and telephone questionnaires conducted through the following questionnaires: Information Collection Questionnaire 1 targeting land owners and community members; Information Collection Questionnaire 2 targeting the main five concerned service authorities; and Information Collection Questionnaire 3 targeting urban planners within the GDUP [3], to help in validating the developed urban planning process.

- Meetings conducted with concerned parties as an application of the developed urban planning process using participatory planning and QFD.

After analyzing and reviewing the findings, an explanatory case study technique is used as a qualitative research methodology to help in reaching the aim of this research in a systematic and comprehensive manner. A new improved urban planning process was developed through the implementation of participatory planning and the application of QFD to mitigate the gaps found in the existing procedure. A case study was then selected (North Tubli), to evaluate the modified urban planning process. Finally, the developed process was validated using the Delphi method.

\section{DEVELOPMENT OF THE NEW URBAN PLANNING PROCESS}

Based on the previous literature review and the selected research methodologies, and after thoroughly investigating the existing urban planning process followed in Bahrain, a new urban planning process has been developed using participatory planning and QFD.

Using QFD as a technique to develop the urban planning process can be achieved by constructing 3 matrices, that are called Houses of Quality (HOQ1, HOQ2 and HOQ3) [10] . As shown in 'see Figure 1', the three matrices represents the following phases:

- $\quad$ Planning matrix: deployment of the Bahrain national 2030 plan10 strategies.

- Design matrix: deployment of services limitations.

- Design matrix: deployment of design limitations. 


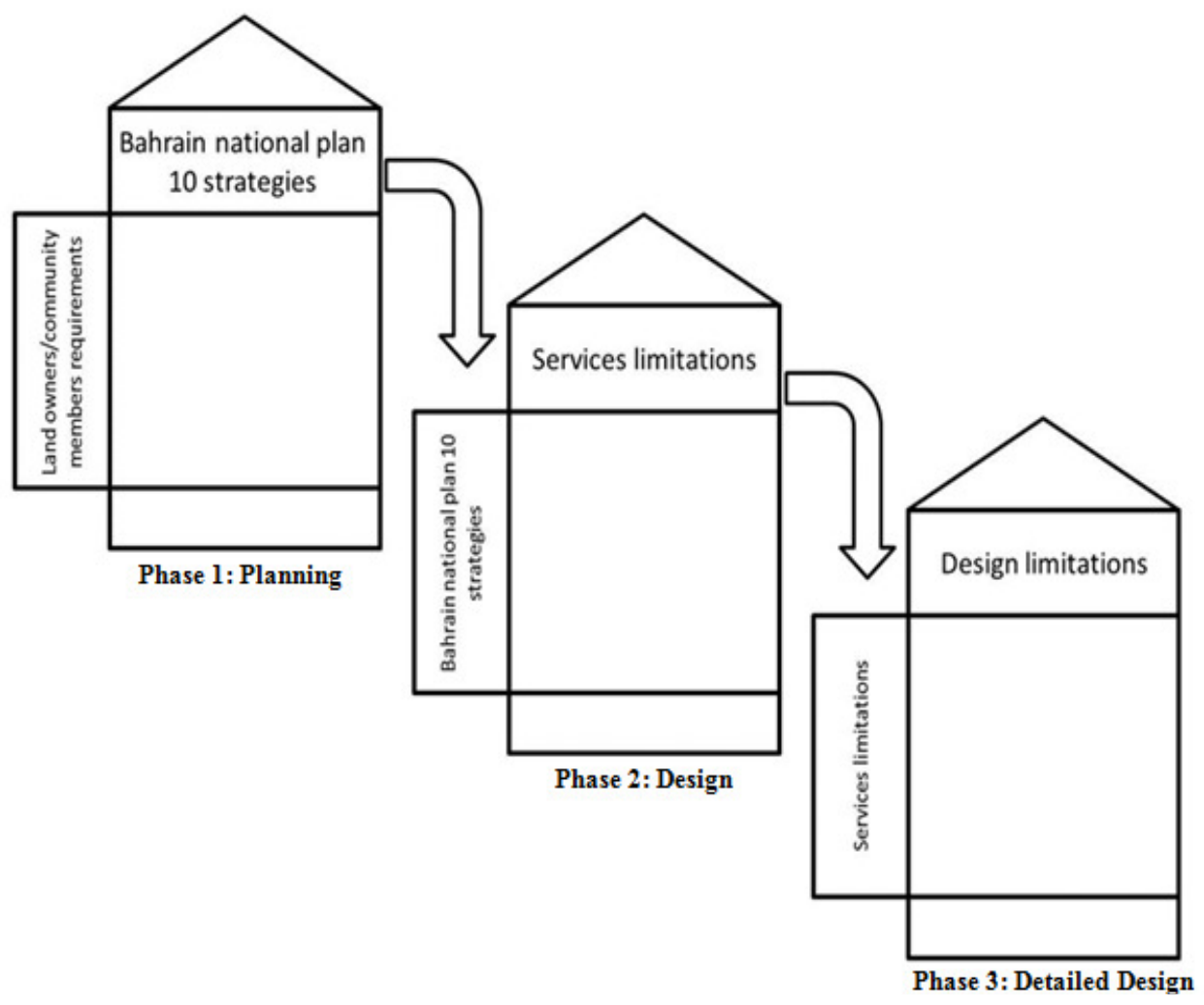

Figure 1.QFD phases

The new developed urban planning tool is a systematic process that can be followed throughout the design stage in all detailed plans that will be created in the future. 'As in Figure 2', the developed process consists of four stages; each stage ends with an output that leads into the next stage input.

Stage 1 is initiated by selecting the boundaries of the study area. A study of the selected area is conducted by the urban planners in which they contact Survey Land Registration Bureau (SLRB), to get a list containing the names and contact numbers of lands' owners of the selected study area. The urban planners visit the selected site to document the existing condition of the build-up environment. A site analysis report containing the mentioned list and photographs of the existing build-up environment within the selected lands (existing buildings, services, roads, and plantations), is then produced. Information Collection Questionnaire 1 is then filled by urban planners after contacting the land owners and community members, who are the residents of the adjacent residential areas that can be affected by the future development of the selected study area, to identify their needs and requirements. The Analytical Hierarchical Process (AHP) is used to establish the importance ratings of these requirements. The output of Stage 1 is a prioritized list of land owners and community members' requirements that will be used in HOQ 1 of Stage 2. 
Civil Engineering and Urban Planning: An International Journal (CiVEJ ) Vol.4, No.1, March 2017

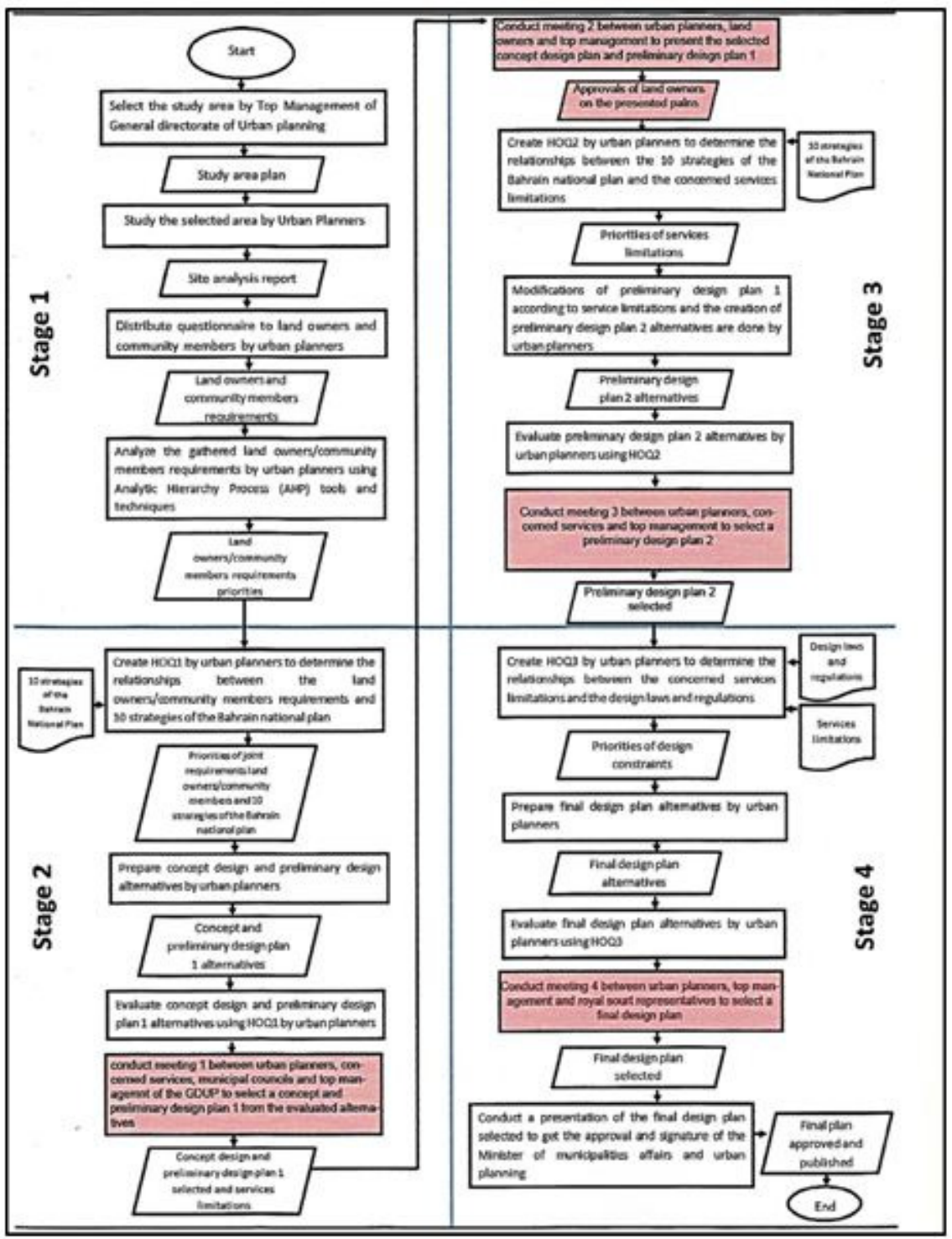

Figura 2. Daveloped urban planning procass

Stage 2 stats with the creation of HOQ1, in which the requirements of the land owners and community members and their importance ratings represent the "customer voice", while the "Bahrain national 2030 plan 10 strategies" represent the "manufacturer voice", 'as in Figure 3". In this step, the priorities of the "Bahrain national 2030 plan 10 strategies" are established based on the land owners and community members requirements. These priorities are used for the formulation of the concept plan and the different altematives for preliminary design plan $1 . \mathrm{A}$ 
concept design plan consisting of zoning areas (land uses) including preliminary road network is then prepared by urban planners. This is followed by the preparation of alternatives for preliminary design plan 1. Using HOQ1, the concept design plan and the alternatives of preliminary design plan 1 are evaluated by urban planners, to ensure that the land owners and community members requirements have been met in each alternative. The first meeting is then conducted between urban planners and the concerned services. During this meeting, representatives of the services authorities provide their comments on the alternatives of preliminary design plan 1 , highlighting the locations, sizes, reserved areas, and limitations on developments of the existing and requested services. As a result of this meeting, the most suitable concept plan and the alternatives of preliminary design plan 1 that satisfies landowners, community members, and services requirements are selected, which concludes Stage 2.

Stage 3 starts with the creation of HOQ 2, 'as in Figure 4'. It is designed to establish the importance ratings of the "services limitations", as a result of their relational comparison with the "Bahrain national 2030 plan 10 strategies". Based on the output of HOQ 2 (priorities of services limitations), modifications are done by urban planners to the selected preliminary design plan 1 to match these limitations. Thus, the different alternatives of preliminary design plan 2 are developed and evaluated by urban planners to show how the "Bahrain national 2030 plan 10 strategies" have been met for each alternative. The second meeting is then conducted among urban planners, concerned services, municipal council representatives, and royal court representative. The result of this meeting is the selection of the most suitable preliminary design plan 2 that satisfies "services limitations" and the requirements of the participating parties, this concludes Stage 3.

Stage 4 begins with the creation of $\mathrm{HOQ} 3$, 'as in Figure 5'. It is designed to establish the importance ratings of the "design constraints" as a result of their relational comparisons with the "services' limitations". The "design constraints" used in HOQ 3 include building construction, lands subdivision, land acquisition laws and regulations used recently in Bahrain. Sorting out the priorities of "design constraints" in HOQ 3 helps urban planners to modify the best alternative of preliminary design plan 2 that has been selected in the second meeting. Hence, alternatives of the final design plan are generated and evaluated by urban planners to show how the "services' limitations" have been met for each alternative. The final meeting is held between urban planners and the top management of the GDUP. This meeting results in selecting the most suitable final design plan that satisfies design standards and the services limitations. After the approval of the best final design plan by the top management of GDUP, the selected plan is presented to the Minister of Municipalities Affairs and Urban Planning to get his approval and accreditation (signature) before publishing the plan to the public. This is the last step in the new urban planning process to develop a final design plan of the selected area ready for implementation.

\section{EVALUATION OF THE DEVELOPED URBAN PLANNING PROCESS}

A thorough investigation has been conducted to select an area as a case study (study area) from the 20 approved final design plans during the first decade of this century. The area selected is located in the three cadastral blocks of North Tubli area, which is located in the Capital Governorate of Bahrain according to the recent blocks distribution. This area spreads on an approximate 82.54 hectare, and it consists of 120 lands (plots), 'as in Figure 6'. 
Civil Engineering and Urban Planning: An International Journal (CiVEJ ) Vol.4, No.1, March 2017

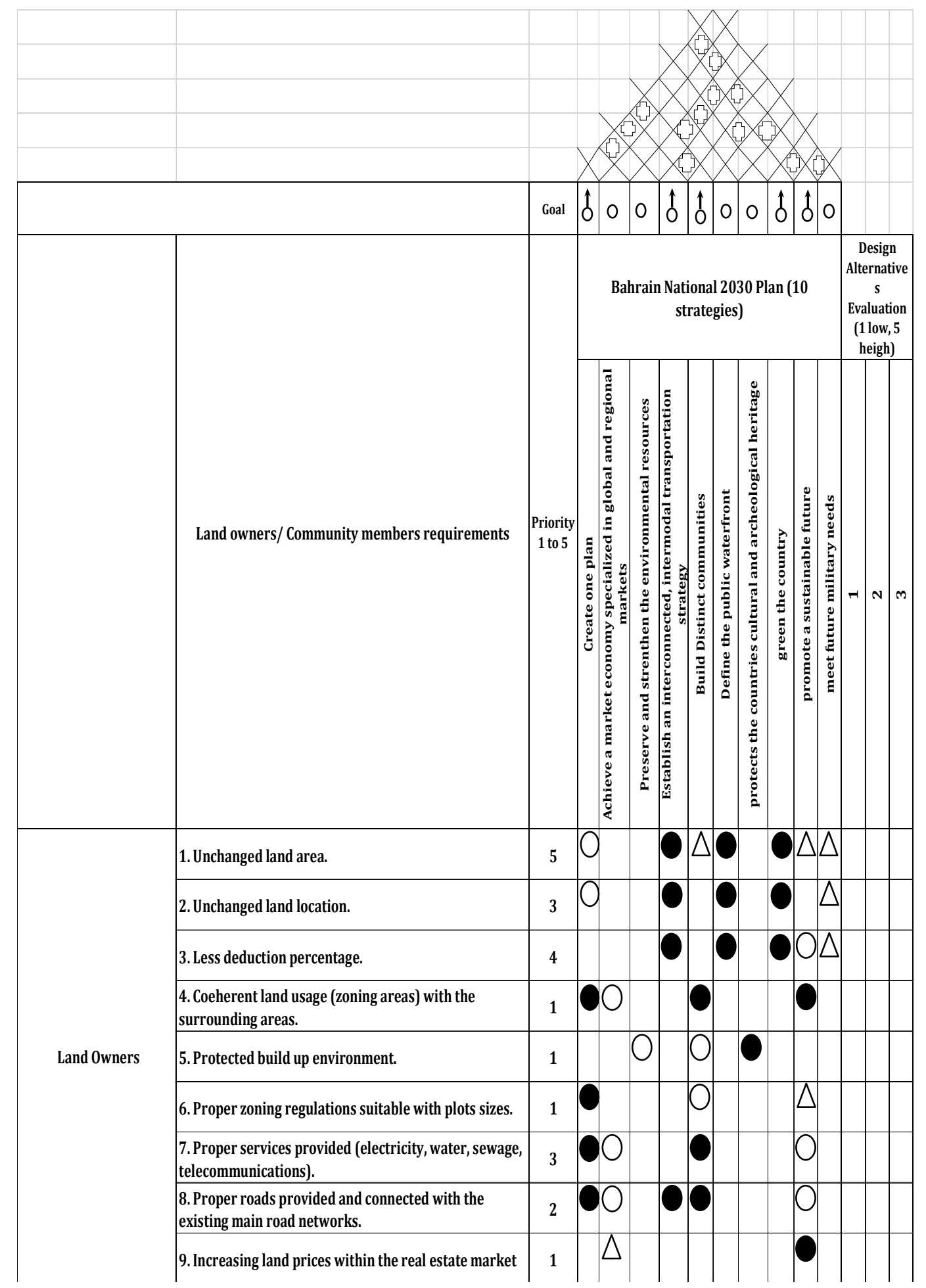

Figure 3. HOQ1 


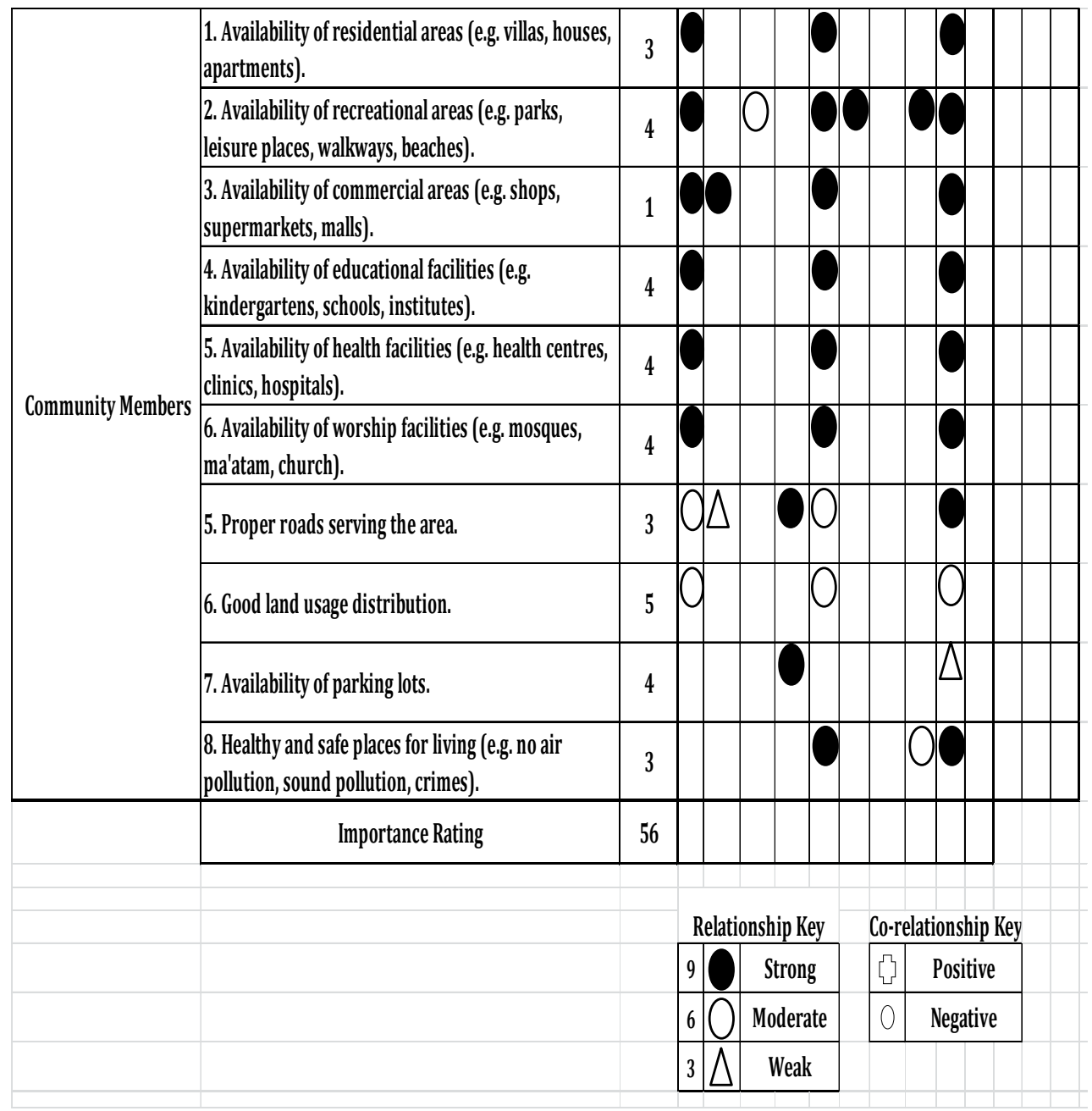

Figure 3. HOQ1(Cont.)

The urban planning of this area has been designed in 2006, since then it has been facing many changes and delays during the implementation stage. The main cause of the constant changes and delays in implementation was due to the dissatisfaction of the land owners with the deduction percentage. Generally, the deduction results in total land area reduction, land relocation, and large lands subdivision. In this section the discovered gaps during the design stage are identified and compared with the results of applying the developed urban planning process using participatory planning and QFD.

The stakeholders who were involved in the validation and evaluation of the developed urban planning process are 47 land owners, 100 community members, 43 urban planners, 19 representatives of services authorities, one representative of Royal Court, and 3 from the top management of GDUP. These stakeholders were involved in the application of the developed process to the case study through questionnaires. Three questionnaires have been designed, targeting three main groups of the above stakeholders who are considered to be the back bone of the application of participatory planning and QFD in the developed urban planning process. The first questionnaire, addressed the land owners and community members of the selected study area. The second questionnaire, addressed the concerned services authorities. The third questionnaire, addressed the professional urban planners. 
Civil Engineering and Urban Planning: An International Journal (CiVEJ ) Vol.4, No.1, March 2017

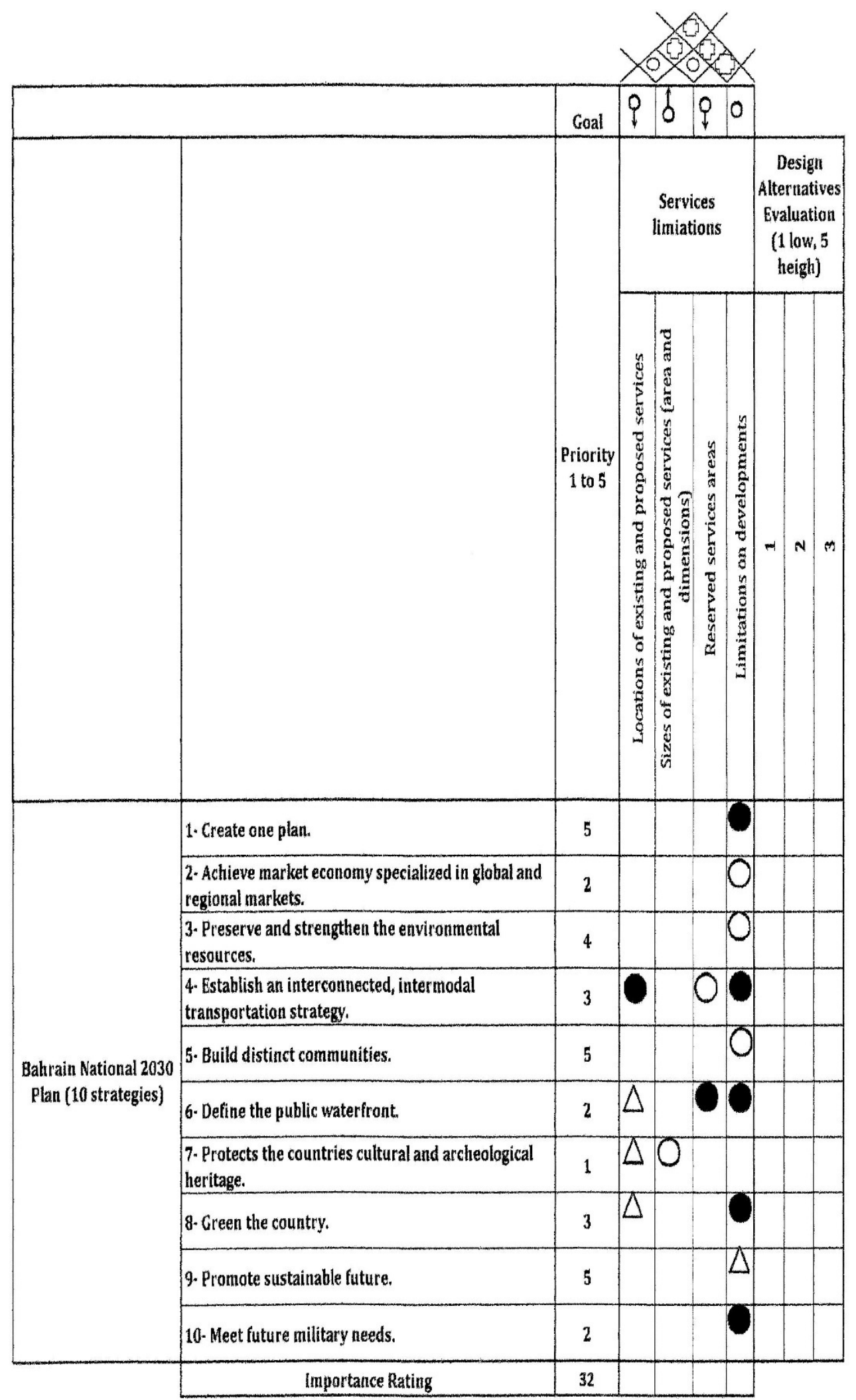

Figure 4. HOQ2 
Civil Engineering and Urban Planning: An International Journal (CiVEJ ) Vol.4, No.1, March 2017

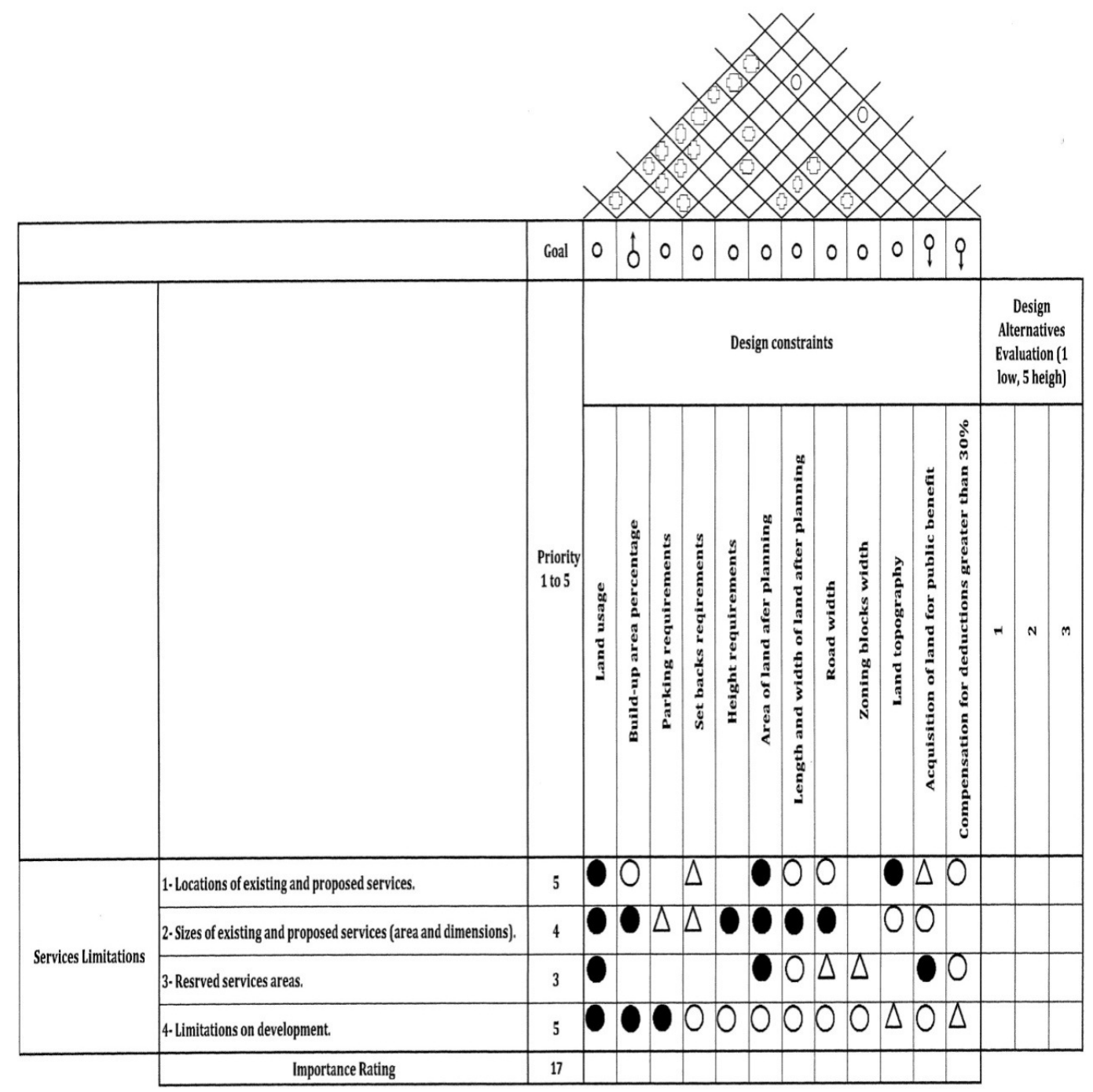

Figure 5. HOQ3

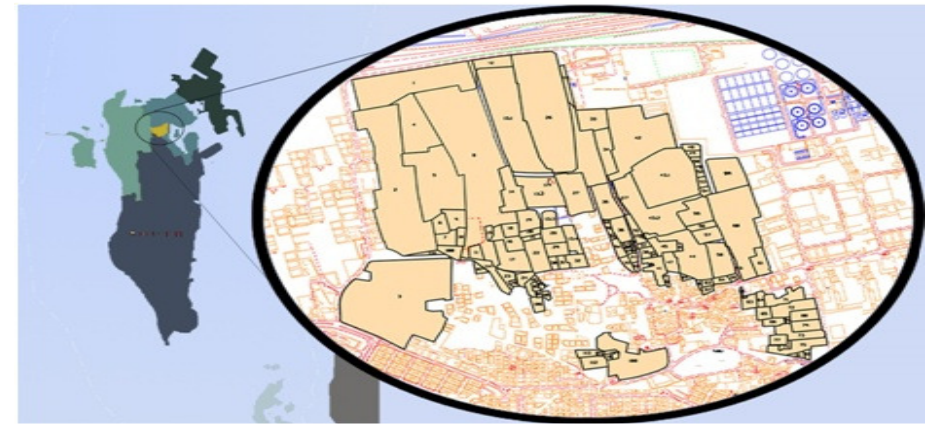

Source: The General Directorate of Urban Planning

Figure 6. Selected study area location 
The Developed Urban planning Process was applied on the selected study area, using participatory planning and QFD, as previously mentioned. The HOQ 1, 2 and 3 application resulted in highlighting the areas that needed to be addressed while preparing concept design plan, preliminary design plan 1, preliminary design plan 2, and the final design plan. The developed urban planning process and the results generated from the application of QFD were validated and evaluated for acceptability and reliability, through survey questionnaires and Delphi method.

\section{DISCUSSION}

The development of an urban planning process is an important issue to be tackled, because it has direct effect on the economical, industrial, financial, and tourism sectors in Bahrain. The existing process has created many distinguished plans that have not been fully implemented, mainly due to land owners objection with proposed plan designs (90\%), and flaws in the process itself. In addition, the data analysis revealed that $46 \%$ of the participants agreed that the urban planning process currently followed in Bahrain needs modification, and 55\% of them were partially satisfied with the mentioned process. Therefore, a new process had to be developed to solve these problems and prevent them from re-occurring. The purpose of introducing Participatory Planning concept in the urban planning process was an essential aspect to ensure both land owners and community members involvement in the land design. Analysis of the case study data revealed that $62 \%$ percent of the land owners have not been contacted before the application of the urban planning process on their lands, which means that participatory planning has not been applied in the urban planning process currently followed in Bahrain. Moreover, $60 \%$ of the land owners were not involved during the application of urban planning process on their lands. Accordingly, $68 \%$ of the surveyed land owners were in favor of participating in the plan design stage. After introducing participatory planning as a concept, it was apparent that there was a need for applying a technique that helps in transferring the qualitative data into quantitative data to ease the measurement, assessment and evaluation of the stakeholders' requirements. Accordingly, the QFD technique was incorporated in a clear structured urban planning process ready to be applied in Bahrain.

The historical data analysis along with interviewing 75 land owners, 10 engineers representing 5 services authorities, and 28 professional urban planners from the GDUP, revealed the following limitations with the current urban planning process application on the design plans of North Tubli area in 2006:

- $\quad$ No considerations were given to land owners or community members requirements.

- $\quad$ No serious considerations were given to "Bahrain national 2030 plan 10 strategies".

- No tools were used to rank the services and other authorities requirements.

- $\quad$ No meetings were conducted with the participating parties.

- The services were consulted one time only.

- Decisions were taken based on urban planners and top management opinions.

After applying the developed urban planning process on the case study the results and analysis were reviewed and validated by the five service authorities, professional urban planners, and the top management of GDUP through the Delphi method. The group of experts evaluation and validation drew attention to the following improvements:

- Provision of participatory planning gave land owners and community members the opportunity to participate in the application of urban planning process. 
- Major participating parties were defined as a first step prior to the application of the developed process.

- Serious considerations were given to all parties' requirements, including "Bahrain national 2030 plan 10 strategies".

- The provision of multiple alternatives gave all participating parties the opportunity to select a single alternative, which satisfies most of their requirements without making major compromises.

\section{CONCLUSION}

The developed urban planning process using participatory planning and QFD addressed the difficulties and delays encountered during the application of the current urban planning process followed in Bahrain. The developed process was based on a case study and validated through Delphi method. Three main contributions were achieved from conducting this study. The first contribution was the assurance of the incorporation of new participating parties (mainly the land owners and community members) before and during the application of the urban planning process. The second contribution was the creation of a systematic methodology to support urban planners in setting out importance ratings for all the factors that should be considered during the different design stages. The final contribution was enabling the urban planners to evaluate different design alternatives and select the most suitable alternative.

The developed urban planning process was applied on a location with a limited area, which provided limited results specific to that particular area. However, the top management of GDUP [3] is interested in applying the developed process in the near future. Therefore, future studies will examine the implementation on different plots in Bahrain. Furthermore, a software package will be created to simplify the developed urban planning process application and results analysis.

\section{REFERENCES}

1. Bracken I., (1981) "Urban planning Methods: Research and Policy Analysis”,Methuen \& Co. Ltd., London.

2. Hall P. \& Tewdwr-Jones M., (2011) "Urban and Regional Planning”,Routledge, London.

3. GDUP, (2014) "General Directorate of Urban Planning Report", Ministry of Works, Municipalities Affairs and Urban Planning, Bahrain.

4. Keeble L., (1952) "Principles and Practice of Town and Country Planning", The Estates Gazette, London.

5. McLoughlinJ., (1969)“Urban and Regional Planning: A systems Approach”,Faber and Faber, London.

6. Ataöv A., (2008)“Constructing Co-generative Search Process: Re-thinking Urban Planning/ Making Urban Plans Actionable”, Journal of European Planning Studies, Vol. 16, No.6, pp829-851.

7. Taylor N., (1998)“Urban planning Theory since 1945”,Sage Publications Ltd., London.

8. Balta M., Tekel A.\&Tekel H., (2012)"Urban Development Process of Built Environments in Metropolitan Areas in Turkey: Case Study of Angora Settlement, Ankara”,Journal of Urban Planning \& Development, Vol. 138, No.1,pp 70-77.

9. Türk Y., Bayram Z., Sagsoz A., (2011) "Evaluating the Developmental Process of the Zoning Regulations in Turkey in Terms of Urban Design”,International Journal of academic research,Vol. 3, No.1, pp 580-584.

10. Suliman S., (2006)“Application of QFD in Engineering Education Curriculum Development and Review”, International Journal ContinuingEngineering and Life-Long Learning,Vol. 16,No. 6, pp 482492.

11. Chou S., (2004) “Evaluating the Service Quality of Undergraduate Nursing Education in Taiwan using Quality Function Deployment",Journal of Nurse Education Today, Vol.24, No.1,pp 310-318.

12. Sher S., (2006)“Application of Quality Function Deployment (QFD) in Product Development: The Case Study of Taiwan Hypermarket”. Journal of AmericanAcademy of Business, Vol. 8, No.2, pp 292295. 
Civil Engineering and Urban Planning: An International Journal (CiVEJ ) Vol.4, No.1, March 2017

13. Almannai B., Greenough R.M., Kay J.M., (2008) " A decision support tool based on QFD and FMEA for the selection of manufacturing automation technologies". JournalRobotics andComputer-Integrated Manufacturing, Vol.24, No. 4, pp501-507.

14. Boonyanuwat N., Suthummanon S., Memongkol N., and Chaiprapat S., (2008) "Application of Quality Function Deployment for Designing and Developing a Curriculum for Industrial Engineering at Prince of Songkla University”,Songklanakarin. Journalof Science andTechnology, Vol. 30, No. 3, pp 349-353.

\section{Authors}

Noora Buchiri is chief of development control section, towns \& villages planning directorate, general directorate of urban planning, working inMinistry of Municipalities Affairs and Urban Planning. She holds Masters Degree in Engineering Management andBachelors Degree. Fields of interest:Urban Planning, Engineering Management, and Quality Management.

Bader Al Mannai is an Assistant Professor in the Department of Mechanical Engineering, University of Bahrain. Fields of interest: Quality Management, Manufacturing Management, Quality Service, engineering Economy.

Saad M. A. Suliman is a Professor in the Department of Mechanical Engineering, University of Bahrain.Fields of interest: Manufacturing Systems and Processes,production planning and control, reliability engineering, performance evaluation, and project management.
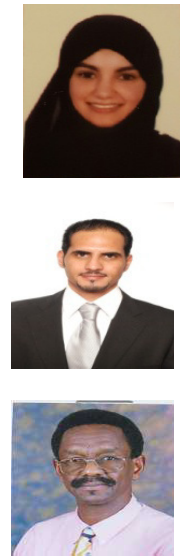